\title{
DROGADIÇÃO, PRIVAÇÃO E CONFLITO COM A LEI: REFLEXÕES
}

\author{
Bruna Martins ${ }^{1}$ \\ Giorgia Reis Saldanha ${ }^{2}$ \\ Edna Linhares Garcia ${ }^{3}$ \\ Dulce Grasel Zacharias ${ }^{4}$
}

\section{RESUMO}

Este artigo apresenta reflexões sobre a relação estabelecida entre dependência química, delinquência e desenvolvimento emocional do sujeito a partir da análise de dados da pesquisa A realidade do crack em Santa Cruz do Sul (2a etapa): uma investigação sobre os sentidos produzidos nos discursos de usuários e de familiares. Foram entrevistados 100 usuários de crack e 100 familiares, contatados por meio de seus vínculos com serviços de saúde (ESFs, CAPS, hospitais, etc.). A alta porcentagem do envolvimento dos sujeitos com a polícia levounos a problematizar a questão da delinquência à luz da teoria winnicottiana, propondo reflexões que interrogam discursos que estabelecem relações de causalidade linear entre delinquência e uso de drogas. As análises apontam para histórias perpassadas por privação familiar e de suporte continente, existências pouco cuidadosas de si mesmas e do outro, subjetivações desejantes de enlaces afetivos, possivelmente malogrados, ao longo do desenvolvimento emocional.

Palavras-chave: Drogas. Privação familiar. Delinquência.

\section{ABSTRACT}

This paper presents reflections about the relationship established between substance dependence, delinquency and subject's emotional development by analyzing data from the research The crack reality in Santa Cruz do Sul ( $2^{\text {nd }}$ phase): an investigation into the meanings produced in discourses of drug users and their relatives. One hundred crack users and 100 relatives were interviewed. The subjects were found through their links to health services (ESFs, CAPS, hospitals, etc.). The high percentage of subjects' involvement with the police caused us to problematize the delinquency issue in light of the winnicottian theory, by proposing reflections questioning the discourses that establish linear causality relationships between delinquency and drug addiction. The analyses have pointed out stories pervaded by both family deprivation and lack of support, lives with little care of both themselves and the others, subjectivities longing for affective bonds, which were probably unsuccessful, throughout their emotional development.

Keywords: Drug. Family deprivation. Delinquency.

\footnotetext{
${ }^{1}$ Acadêmica de Psicologia da Universidade de Santa Cruz do Sul - UNISC. <bruna.lopes.martins@ hotmail.com>.

2 Acadêmica de Psicologia da Universidade de Santa Cruz do Sul - UNISC.

${ }^{3}$ Doutora, professora do Programa de Pós-Graduação Mestrado em Promoção de Saúde e do Departamento de Psicologia da Universidade de Santa Cruz do Sul. 〈edna@unisc.br>

${ }^{4}$ Mestre, professora Departamento de Psicologia da Universidade de Santa Cruz do Sul - UNISC. <dulce@unisc.br>
} 


\section{INTRODUÇÃO}

O homem tem construído sua história enredada no uso de drogas como uma das possibilidades de fontes de prazer. De acordo com Bucher (1988, p. 1), "a história do homem em seus mitos e lendas está repleta de exemplos de revolta contra as contingências que limitam seu desejo de transcendência, em que ele busca a imortalidade, o prazer e o saber, através do uso de drogas". Nesse sentido, o uso do termo "enxugar gelo", utilizado por Tófoli (2014) para referir-se à política de combate que visa ao extermínio do uso das drogas, nos diz do fracasso ao qual já nasce condenada tal política, diante da impossibilidade de estancamento do desejo que, por inusitados vieses, não cessa de reeditar-se.

Russo (2011) afirma que as alternativas de guerra às drogas surgem da sociedade mobilizada e que a discriminação não resolve nenhum dos graves problemas ligados a drogas. Do nosso ponto de vista, a complexidade que envolve a problemática decorrente do uso e dependência de drogas requer uma escuta da história singular do sujeito.

Nessa perspectiva, por meio da análise dos sentidos produzidos pelos familiares de usuários de drogas em situação de dependência, identificamos a presença de conflitos relativos, entre outros, ao efeito moral das contingências em que os usuários fazem uso dessas drogas, em especial do crack. Buscando uma análise que garanta a complexidade e a profundidade dessa relação, neste artigo apresentamos problematizações construídas a partir da leitura e das reflexões sobre os dados referentes às entrevistas realizadas com 100 sujeitos usuários de crack. Estas foram conduzidas pelo grupo da pesquisa A realidade do crack em Santa Cruz do Sul da Universidade de Santa Cruz do Sul, no ano de 2010, a qual, em sua ampliação nesta segunda etapa, possibilita uma investigação sobre os sentidos produzidos nos discursos de usuários e de familiares atualmente.

Priorizamos uma questão específica da entrevista, a qual indagava os usuários se já haviam se envolvido com a polícia. A partir dos sentidos que se produziram em decorrência dessa pergunta, buscamos compreender algumas relações estabelecidas entre uso de drogas, delinquência e desenvolvimento emocional, numa perspectiva que se distancia de uma compreensão causal e linear. Para assegurarmos a complexidade dessa relação, lançamos mão de argumentos da teoria psicanalítica, especificamente do psicanalista Donald Winnicott. Esse teórico muito contribuiu para uma maior compreensão da constituição subjetiva, por meio de um extenso trabalho clínico com bebês e crianças, possibilitando o reconhecimento da importância do meio emocional no desenvolvimento das doenças físicas e no desencadeamento das angústias. Sublinhamos que, a partir de suas elaborações, é possível 
destacar uma compreensão da delinquência que traz implicações para a intervenção e aos cuidados relativos à prevenção, neste caso, no âmbito do uso em excesso de drogas.

A título de ilustração, apresentamos a discrepância entre o envolvimento dos usuários com a polícia e o não envolvimento. Esses dados foram colhidos de 100 entrevistas realizadas com os usuários, visto que a pergunta era objetiva e clara: você já se envolveu com a polícia?

Verificamos que $79 \%$ dos entrevistados já tiveram envolvimento com a polícia, e apenas $21 \%$ não haviam tido nenhum envolvimento. A alta porcentagem do envolvimento dos sujeitos com a polícia levou-nos a problematizar a relação entre o uso de drogas e a delinquência, pois os dados podem facilitar ou sustentar uma compreensão de relação unicausal, linear e determinista. Optamos pela discussão desses dados na medida em que dispomos de muitos sentidos que os encontros com os discursos desses sujeitos nos permitiram. Lançamos mão, para nosso intento, da perspectiva teórica psicanalítica por considerarmos que permite uma compreensão da questão da delinquência e do desenvolvimento emocional de sujeitos cuja história se constrói perpassada por privação familiar e falta de suporte continente. Essas circunstâncias que identificamos em nossos sujeitos podem ter contribuído para gerar existências tão pouco cuidadosas de si mesmas e do outro, mantendo-os em eterno estado de compulsão à repetição na busca e no uso da droga, no caso, o crack. Nesse sentido, a teoria winnicottiana propõe identificar uma subjetivação desejante de um afeto que pode ter sido inconscientemente falho.

\section{O USO DE DROGAS: UM RECORTE NOS DISCURSOS}

Inicialmente, torna-se necessário apresentar a inquietude que nos alcança quando do uso do termo "dependente" para identificar ou referir-se ao usuário de drogas. Em primeiro lugar, porque isso remete a uma ideia essencialista e definidora do sujeito, definitiva e exclusivamente, como um dependente de droga. Em segundo lugar, porque o uso de drogas e a experiência de sua repressão são também construções sociais.

Petuco (2012) assinala a necessidade de debruçarmo-nos diante dessa terminologia. Tal como em outros tempos, pensou-se sobre as diferentes terminologias usadas para definir um grupo social; por exemplo, o doente mental passou a ser nomeado de "portador de sofrimento psíquico", e os leprosos, "de portadores de hanseníase”. Citando Michel Foucault (1999), o autor relembra o quanto os discursos sanitários compõem os discursos que findam por produzir subjetividades para além do sujeito em si. A cada dia deparamo-nos com o 
aumento do consumo de drogas, bem como com suas consequências tanto para o sujeito usuário quanto para a sociedade como um todo.

Foucault (2007), em Microfísica do Poder, compõe um relato da trajetória da medicina social. Torna-se evidente a produção de modos construídos como padrões de acordo com as necessidades de cada Estado, compreendendo que a força dos corpos seria a força do Estado. Na França, no século XIII, ao iniciar-se uma revolta urbana da plebe e dos camponeses, a cidade começou a perder o controle que até então estava estabelecido; em consequência disso, surgem mais doenças e instala-se um caos, produzindo medo e pânico na população. Diante dessas circunstâncias, o governo institui uma prática higienista, uma medicina social urbana que tem no seu eixo central a vigilância e a exclusão, visando à purificação do espaço urbano.

Contemporâneos do mundo dos especialismos, assistimos à definição dos fatores biológicos e psicológicos que influenciam o uso de drogas. Ressalta-se que a força dessa influência se estabelece em diferentes graus nos indivíduos. Os fatores biológicos dizem respeito às diferenças individuais quanto à resposta de cada sujeito à droga, considerando-se sexo, idade e herança genética. Já os fatores psicológicos incluem todo o desenvolvimento e as dificuldades emocionais, assim como problemas comportamentais e cognitivos que findam por aumentar os riscos e a resistência (WASHTON; ZWEBEN, 2009). Temos, assim, uma análise que tende a abstrair a força de outros fatores que compõem o processo de produção de subjetividades daqueles que usam a droga em excesso.

Segundo Bucher (1988), é de grande importância conhecermos a classificação e os grupos das drogas, pois seus efeitos podem variar segundo a dose utilizada por cada indivíduo, o tempo de utilização e a forma ou via de administração. Encontramos em Macedo (2008) algumas questões importantes a serem consideradas no uso das drogas. Tais questões remetem-nos para além do uso abusivo das substâncias e da dependência, pois perpassam conjuntos de fenômenos, tais como o sofrimento dos indivíduos, das famílias e dos grupos sociais. Como fatores determinantes para desenvolver a dependência do uso de drogas, a autora destaca a herança familiar, a psicopatologia, a cultura, o ambiente familiar, a pressão de grupo e outros estressores psicossociais. Nessa perspectiva, encontramos o reconhecimento de que se trata de um fenômeno multideterminado e que exige, quando tomado em análise, a necessária consideração de sua complexidade. Petuco (2012) ressalta que:

Um fenômeno tão complexo requer abordagens igualmente complexas, que apenas a perspectiva da rede é capaz de oferecer. E quando falo em "rede" não falo apenas nas redes intersetoriais de atenção (ainda que estas sejam fundamentais!), mas também de um exercício de complexidade na hora de olhar para aquilo que possa 
eventualmente contribuir para a ampliação da vulnerabilidade e sofrimento de usuários e usuárias de drogas [...] (p. 26).

Em acordo com o autor acima referido, compreendemos que, diante da problemática decorrente do uso em excesso ou da dependência de droga, a tendência à simplificação deve ser exaustivamente combatida, pois pode produzir irreversíveis complicações para os sujeitos envolvidos, impossibilitando que sejam atendidos devidamente no campo dos cuidados em saúde. A atenção em saúde deve ser realizada considerando o sujeito na sua integralidade, o que implica levar em conta aspectos e condições presentes ao longo do processo de sua constituição subjetiva.

\section{DESENVOLVIMENTO EMOCIONAL: UM RECORTE NA TEORIA DE WINNICOTT}

A propósito dos aspectos psicológicos, torna-se indispensável abordar o desenvolvimento emocional desde o nascimento do indivíduo. Winnicott (1965), em A família e o desenvolvimento individual, retoma a importância dos primeiros anos de vida no desenvolvimento emocional do sujeito, ressaltando que marcas significativas se instauram nesse período, mas também no período pré-natal. Ainda que o termo "desenvolvimento" não veicule um sentido evolucionista, em que um estágio seguinte suplanta o anterior, Winnicott utiliza sua teoria sobre os estágios iniciais para falar sobre o desenvolvimento da personalidade e do caráter. Refere que, quando se constata que um sujeito começa a sentar, por volta dos cinco ou seis meses, ou que começa a caminhar, por volta dos 12 meses, não se encontram apenas fatores biológicos que possibilitam esse crescimento. Para o autor, o crescimento natural dependerá de condições suficientemente boas ofertadas pelo meio onde o sujeito está imerso.

No primeiro ano de vida da criança, o grande marco é a aquisição da independência, que só pode desenvolver-se a partir de um estado de dependência, o qual o autor nomeia de “dupla dependência". Nos primórdios da vida do bebê, essa dependência é absoluta em relação ao ambiente físico e emocional e passa-se em nível inconsciente. Gradativamente, a criança toma conhecimento dessa dependência e mostra para o ambiente, de diversas formas, suas necessidades. Importante assinalar que esses períodos não são estáticos, visto que certo grau de dependência pode ser inúmeras vezes conquistado e perdido. O desenvolvimento, que ocorre de forma progressiva da dupla dependência à dependência, para em seguida alcançar a independência, somente é possível se o bebê puder contar com outra pessoa que se faça 
adaptar às suas necessidades. Entende-se que essa outra pessoa é, comumente, a mãe ou quem exerce a maternagem para esse sujeito (WINNICOTT, 1965).

A maturidade de um ser humano não implica somente sua capacidade de crescimento, mas também sua capacidade de socialização. Dessa forma, no âmbito da saúde, falamos em capacidade de socialização sem demasiado sofrimento, ou seja, sem precisar ser antissocial para evitar o intenso sofrimento que esse intuito pode implicar. O desenvolvimento emocional não caracteriza um indivíduo independente de forma absoluta, uma vez que ambiente e indivíduo são interdependentes (WINNICOTT, 1983).

Para melhor compreensão do desenvolvimento emocional, Winnicott elencou três dimensões desse processo, sendo elas: dependência absoluta, dependência relativa e rumo à independência. Na dependência absoluta, o bebê fica à mercê e completamente dependente da mãe, incluindo o útero materno e os cuidados necessários após o nascimento. O bebê nasce com suas heranças genéticas que favorecem a sua característica de personalidade, porém é o ambiente que torna possível o processo de maturação, bem como a concretização do potencial da criança (WINNICOTT, 1983). Importante assinalar a distância que se estabelece entre essa ideia e a teoria freudiana, uma vez que Freud (1972) não considera uma herança genética, mas uma herança psíquica que influencia nossos modos de constituição.

A chamada "preocupação materna primária" torna-se fundamental nessa dinâmica, consistindo no processo em que a mãe se coloca totalmente disposta e devota a seu bebê, durante a gravidez e nas primeiras semanas. A preocupação da mãe com o bebê é tamanha que este se torna parte dela, de modo que ela se utiliza das suas próprias experiências imaginárias como bebê para exercer o cuidado, o que caracteriza o termo "dupla dependência". Winnicott chama a atenção para a existência do que ele denominou de "necessidades do ego", as quais transpassam as necessidades "instintivas" da criança. Ressalta, ainda, que a capacidade da mãe em devotar-se ao bebê protege a sua capacidade de vir a ser e que qualquer falha nessa adaptação pode tornar-se uma falha no vir a ser desse sujeito. Essa vivência evidencia-se até os seis meses de idade (WINNICOTT, 1983).

Na dependência relativa, o bebê começa a utilizar-se de uma compreensão intelectual para dar conta das suas necessidades, como, por exemplo, se ouve barulho na cozinha, percebe que a comida está sendo feita. Porém, o desenvolvimento saudável dessa capacidade intelectual dependerá de um espaço continente, ou seja, um cuidador que mantenha, minimamente, um equilíbrio, fazendo com que a criança se sinta segura. Essa fase ocorre aproximadamente dos seis meses aos dois anos de idade (WINNICOTT, 1983). 
O período intitulado "rumo à independência" depende necessariamente de que os dois estágios anteriores sucedam de forma saudável. Assim, a criança desenvolve recursos para suportar o que recebe do mundo externo e as complexidades da sociedade em que vive, além de uma identificação com essa sociedade, uma vez que esta remete ao seu mundo interno. Esse período consiste na idade pré-escolar e na puberdade, quando a criança, não satisfeita com o estado de dependência, abre mão deste para novas experiências (WINNICOTT, 1983).

$\mathrm{Na}$ perspectiva teórica de Winnicott, espera-se que os adultos continuem a amadurecer ao longo de toda a vida, visto que não se atinge o ápice da maturidade idealizada. Ao trabalhar, casar ou estabelecer uma vida que, de alguma forma, tenha como referência o modelo vivido pelos pais, tem-se, na verdade, a tentativa de estabelecer uma identidade pessoal, partindo-se de uma situação de dependência para outra de independência (WINNICOTT, 1983).

Diante da necessidade de referir-se à importância da função materna, Winnicott (1975) estabelece o conceito de "mãe suficientemente boa", que compreende uma pessoa que gradativamente se adapta às necessidades do sujeito, desde o período da dependência até a independência, em acordo com as necessidades de cada estágio. O autor ressalta que essa função não precisa ser necessariamente exercida pela mãe, mas por uma pessoa que seja capaz de dar o suporte necessário, compreendendo que esse cuidado não depende de uma capacidade intelectual, tampouco de um “jeito" de cuidar, mas de uma devoção (WINNICOTT, 1975).

Nasio (1995), ao referir-se à obra de Winnicott, diz que uma das funções maternas, que se nomeou holding, é nada mais do que a mãe, ou quem exerce função materna, ter a capacidade de dar a sustentação que o bebê precisa. Por meio de cuidados físicos, percebe-se as necessidades da criança, focando-se em suas capacidades auditiva e visual, entre outras, para então estabelecer uma rotina. Isso coloca o bebê numa realidade externa, de modo que, no seu despertar para este mundo exterior, possa encontrar pontos de referência estáveis e sustentáveis.

Ao encontro do conceito de holding, Zimerman (2004) propõe o conceito de continente quando descreve os principais conceitos de Bion. Entende por esse conceito a capacidade da mãe para acolher e conter as necessidades e angústias do bebê, dando conta da carga projetiva que lhe é dirigida.

Lançamos mão da teoria de Winnicott (1987) para também contextualizar a delinquência. Esse teórico propõe a associação da delinquência a uma privação na vida 
familiar. Ressalta que no grupo familiar todos assumem responsabilidade em comum para com os filhos e conseguem, de alguma forma, lidar com os problemas que começam a afetar a sociedade na sua menor instância, a família.

\section{DELINQUÊNCIA E PSICANÁLISE}

Problematizar a delinquência requer que levemos em conta muitos fatores, principalmente em se tratando de uma sociedade que se apresenta com intensas mudanças e instabilidades em seus diversos setores. Contudo, os discursos que permeiam nosso cotidiano, em sua maioria, têm objetivado de tal modo essa questão que acabam por nos oferecer a delinquência como um fenômeno que tem cor e classe social e econômica. Compreendemos que vivemos um tempo que concretiza as condições facilitadoras para a produção desse fenômeno.

Carneiro (2010) assinala que grupos inteiros são alvos da hostilidade social, não por serem necessariamente agressivos, mas apenas por não se enquadrarem nos ideais consumistas. Percebidos como parasitas daqueles que possuem o poder de consumo social estes grupos chocam-se, portanto, com um mundo que oferece uma única forma de validação do eu e uma impossibilidade social e material para realizar esse ideal social. O referido autor contextualiza com precisão: "Eis a armadilha da sociedade contemporânea e do sujeito pósmoderno: livre para ser tudo o que puder, ou tudo o que deve ser, ele se vê diante da angústia da modernidade, isolado e difuso, nada podendo ser de fato [...]” (p.2).

O desenvolvimento da criança não acarreta somente cuidados físicos, ou seja, uma criança não só dorme e come, mas também começa a pôr à prova seu poder de destruição e dissociação, principalmente se tiver dúvidas sobre a estabilidade do lar. Se o lar onde a criança estiver suportar a tentativa de destruição, a criança retornará à sua brincadeira, abstendo-se dessa tentativa. Porém, se perceber que esse lar, que sua referência se desfaz, a criança, aquela que tiver esperança, buscará outras referências, mas deixará de sentir-se livre. O que pode acontecer, nesse contexto, é a criança transportar para a sociedade suas demandas e necessidades, as quais não encontrou satisfeitas na família.

Assim, para Winnicott (1987), quando a criança rouba, está procurando seus cuidadores, mãe e/ou pai, ou seja, aquele outro que poderá dar um limite concreto aos impulsos. Na busca para compreender o fenômeno da delinquência, Melman (1992, p. 44) assinala que as condutas do delinquente devem ser entendidas como simbólicas de uma falta de acesso ao objeto: "não este ou aquele objeto, nem mesmo de objetos dos quais ele faz coleção em sua diversidade heteróclita". 
Winnicott (1983) lança mão da ideia da "culpa" como organizadora de um recurso protetor da criança. Propõe a necessidade do desenvolvimento desse sentimento, possibilitado pelo encontro com o outro, que deve ser rigoroso e amoroso ao mesmo tempo. Ressalta que a capacidade para o sentimento de culpa também estará relacionada aos primeiros estágios do desenvolvimento humano. Dessa forma, considera que esse sentimento está relacionado à capacidade de dar conta da ambivalência. Esta é composta de amor e ódio, propondo o autor que, se a criança conseguir integrar tais sentimentos, estará amadurecendo o ego, que até então era muito fraco. Assim, desenvolverá também a capacidade de preocupar-se e tolerar a ambivalência.

Winnicott (1987), em Privação e Delinquência, novamente faz uma discussão entre as formas eficazes de se obter o sentimento de culpa. Segundo ele, há dois polos que podem ser pensados para essa aquisição, sendo a própria experiência da criança o veículo para tanto. Embora paradoxal, o autor valoriza a experiência da própria criança na descoberta do que é certo e errado, ressaltando o quão menos importante é o comportamento frente à fundamental importância do sentimento do "certo e errado" que a criança pode adquirir independentemente da submissão ao adulto.

Finalmente, Winnicott (1987) conclui que se existe delinquência é porque ainda há o que ser recuperado no desenvolvimento emocional. Nesse sentido, o autor considera que a delinquência é um pedido de socorro dirigido a pessoas fortes, amorosas e de confiança.

\section{CONSIDERAÇÕES FINAIS}

Reproduzir um discurso que coloca o usuário de drogas como sendo um delinquente representa, à luz da teoria winnicottiana, repetir as possíveis falhas ou obstáculos vivenciados por esse sujeito ao longo de seu desenvolvimento emocional. Em decorrência, mantemo-nos distanciados de suas necessidades de cuidado, de suas demandas de amor e de uma escuta dos seus desejos.

Propusemos, neste artigo, a problematização de discursos produzidos e reproduzidos na sociedade que primam pela simplificação ao analisar o fenômeno do uso em excesso e da dependência de drogas. Constatamos, em acordo com outros pesquisadores, que a complexidade que envolve tal fenômeno não permite o estabelecimento de relações lineares ou causais, objetivantes, o que poderia nos levar a continuar "enxugando gelo e sangue" (TÓFOLI, 2014).

Urge a necessidade de ampliação da percepção dos processos envolvidos no desenvolvimento emocional de cada sujeito nos seus contextos - ambiente psicofamiliar e 
social. As experiências e histórias singulares e intransferíveis, perpassadas por conflitos, principalmente no que se refere ao uso de drogas e às suas consequências, incluem ter que lidar com uma nova nomeação, qual seja, "delinquente". Este é mais um elemento com o qual se defronta aquele que já apresenta um sofrimento, que beira as raias do insuportável por não conseguir romper a relação de dependência com a droga. Tal como indicam os dados colhidos nas entrevistas da pesquisa, não basta que sejam "dependentes" - deve ser-lhes imediatamente assegurado um lugar de delinquente.

Ao considerarmos o fator delinquência sustentado nas construções teóricas winnicottianas, procede questionarmos se esses sujeitos usuários de crack não seriam, na realidade, sujeitos desejantes, perpassados por um pedido inconsciente de cuidado, carinho e amor.

Os constructos teóricos apontam-nos o quanto o suporte continente pode garantir um desenvolvimento emocional mais saudável, produzindo uma existência propícia ao cuidado de si mesmo e do outro. Portanto, as problematizações aqui apresentadas favorecem o repensar da drogadição e seus fatores constitutivos, pouco explorados e latentes. Concluímos que a sociedade, na busca incessante de salvar os indivíduos dessa vivência, termina por reproduzir e reforçar diversos pensamentos e estereótipos nada promissores aos sujeitos.

Pensamos que a delinquência expressa, nos sujeitos que fazem parte da pesquisa, uma busca por cuidado, amor e suporte continente para as suas necessidades e demandas. A teoria winnicottiana possibilita tal compreensão na medida em que salienta a importância da afetividade durante o período de desenvolvimento para aqueles sujeitos que, por alguns momentos ao longo da vida, tiveram comportamentos de delinquência.

\section{REFERÊNCIAS}

BUCHER, R. (Org.) As drogas e a vida: uma abordagem biopsicossocial. São Paulo: EPU, 1988.

BURGIERMAN, D. R. O fim da guerra à maconha e a criação de um novo sistema para lidar com as drogas. São Paulo: LEYA Brasil, 2011.

CARNEIRO, J. R. L. Delinquência, exclusão e mídia: Uma contribuição psicanalítica do estudo de adolescentes envolvidos em atos infracionais. Psicologia. O Portal dos Psicólogos, 2011. Disponível em: 〈http://www.psicologia.pt/artigos/ver_artigo.php?codigo=A0561〉. Acesso em: 13 de jun. de 2013

FOUCAULT, M. História da loucura na idade clássica. 6. ed São Paulo: Perspectiva, 1999. 
Microfísica do poder. 24. ed. Rio de Janeiro: Graal, 2007.

FREUD, S. Três ensaios sobre a teoria da sexualidade, in: Obras completas de Sigmund Freud. Rio de Janeiro. Imago, v. VII, 1972.

MACEDO, R. M. S. Terapia Familiar no Brasil na última década. Roca, 2008.

MELMAN, C. Alcoolismo, delinquência, toxicomania: Uma outra forma de gozar. São Paulo: Escuta, 1992.

PETUCO, D. 2012 “Drogas e cidadania” in Conselho Federal de Psicologia, 2014.

TÓFOLI, L., F. Enxugando gelo e sangue. In: FOLHA DE SÃO PAULO. Seção tendências/debates, 20 de janeiro de 2014.

WASHTON, A. M.; ZWEBEN J. E. Pratica Psicoterápica Eficaz dos Problemas relacionados com Álcool e Drogas. São Paulo: Artmed, 2009.

WINNICOTT, D. W. Privação e Delinquência. São Paulo: Martins fontes, 1987.

A família e o desenvolvimento individual São Paulo: Martins fontes, 1965.

- O Ambiente e os Processos de Maturação: Estudos sobre a teoria do desenvolvimento emocional. Porto Alegre: Artes Médicas, 1983.

O Brincar e a Realidade. São Paulo: Ed. Imago, 1975.

ZIMERMAN, D. E. Manual da Técnica Psicanalítica Porto Alegre: Artmed, 2004. 